\title{
DERECHO INDIVIDUAL Y DERECHO COLECTIVO EN TIEMPOS DE CRISIS
}

\author{
INDIVIDUAL RIGHTS AND COLLECTIVE RIGHTS IN TIMES OF CRISIS
}

Ph.D. Edesmin Wilfrido Palacios Paredes

Universidad Central del Ecuador wilfrido.palacios@gmail.com

Fecha de recepción: 09/02/2015

Fecha de aceptación: $16 / 03 / 2015$

\begin{abstract}
Resumen
Comprender los derechos no siempre ha sido fácil, sean estos individuales o colectivos. El pueblo libre y con pleno derecho votó en el año 2008 para aprobar la Constitución del Ecuador en la que se define una Constitución de derechos y no solo de Derecho. Para comprender estos dos conceptos, a lo largo de este artículo, ha sido realizado un recurso de análisis, debates y comparaciones semióticas de las diferentes interpretaciones conceptuales y perceptibles del derecho y derechos, desde la Antropología, la Sociología y la Filosofía.
\end{abstract}

Palabras clave: Antropología, derecho, sociología, derechos y justicia. 


\section{Abstract}

To understand the rights, have not always been easy, be they individual or collective. Free and rightful people voted in 2008 to approve the Constitution of Ecuador in which a constitution of rights and not just law is defined. Throughout this article the readers will understand these two concepts we will make analysis, debates and semiotic comparisons of different conceptual and perceptible interpretations of law and rights, from anthropology, sociology and philosophy.

Keywords: anthropology, law, sociology, rights and justice 


\section{Introducción}

“Estamos obligados a ser libres". Jean Paul Sartre.

Desde la aparición de la socidad civil, la justicia ha jugado un papel fundamental en el bienestar de la sociedad. "Es preciso pues, convenciones y leyes que unen y relacionan los derechos y los deberes y encaminan la justicia hacia sus fines. En el estado natural, en el que todo es común, el hombre nada debe a quienes nada ha prometido, ni reconoce como propiedad de los demás sino aquello que le es inútil. No resulta así en el estado civil, en el que todos los derechos están determinados por la ley" (Rousseau, 1999: p.47). Es decir, que en el estado civil la ley es la expresión de la voluntad general, es el derecho individual organizado de forma colectiva para liberar o condenar legalmente.

En este sentido, Godwin (1945: p.322) dice: "Debemos admitir que somos imperfectos, ignorantes, esclavos de las apariencias. Estos males no pueden ser superados por ninguna acción indirecta, sino sólo por la asimilación de un conocimiento superior".

No descubrimos lo que realmente somos, no somos lo que realmente deberíamos ser y no conocemos nuestros derechos, deberes y obligaciones como seres humanos miembros de un Estado soberano, porque necesitamos de un conocimiento básico para no dejarnos llevar por las apariencias y para ser parte activa en la sociedad.

En nuestra realidad, cuando nos enfrentamos a una injusticia y reclamamos nuestros derechos, no solemos hacerlo por desconocimiento e ignorancia y cuando nos limitan nuestra libertad, siendo acusados de actos que para el Estado y para la sociedad no son legales, necesitamos de alguien que nos represente (un abogado) porque esas son las normas que la sociedad ha impuesto.

Ante esta situación, cabe señalar varias preguntas: ¿quiénes han elaborado las leyes?, ¿las leyes son para todos?, ¿la "justicia” existe para todos?, ¿el Tribunal de Justicia realmente es democrático y hace justicia?, ¿puede ser cualquier ciudadano común miembro del Jurado en el Tribunal de Justicia?

\section{La trascendencia del Juez}

Juzgar ha sido desde tiempos innmemorables una función social claramente ligada a la detentación del poder. Juez ha sido el jefe de la tribu, los ancianos miembros de los consejos de sabios, el sacerdote como vicario de Dios en la tierra o el Rey y sus delegados ad maiorem Dei gloriam.

Superado ese corte epistemológico que supuso la secularización de la política y el nacimiento del Estado, como forma política, se han supuesto notables cambios para la función de juzgar. 
Hace siglos la humanidad superó la época de la ley del más fuerte, la de la venganza privada. Las personas físicas y morales tienen en la actualidad el derecho de llevar sus conflictos y diferencias ante los órganos del Poder Judicial: los tribunales, con la finalidad de que les reconozcan sus derechos. Conforme a la concepción del autor de la conocida obra "El Contrato Social", Juan Jacobo Rousseau (1999), entre los miembros que integran la sociedad existe un contrato o pacto social, del cual se derivan obligaciones y derechos.

Cada ciudadano está obligado a respetar los derechos de los demás y en caso de conflicto, a someterlos ante los tribunales, para que estos sean quienes les den una solución (Rousseau, 1999). La posibilidad de hacerse justicia por sus propias manos ha quedado proscrita, ya que del ordenamiento jurídico se deriva una interdicción absoluta de la denominada venganza privada.

La existencia de Jueces y Jurados imparciales y democráticos constituye un aspecto esencial a la potestad jurisdiccional. El Estado ha evolucionado y se ha dividido en poderes que ejercen el peso y contrapeso del poder público, correspondiendo al poder judicial la función jurisdiccional.

El Juez y los Jurados tienen la obligación de ser neutrales, de mantenerse ajenos a los intereses de los contendientes en el proceso y a ofrecer una solución al conflicto con estricta sujeción al derecho positivo. Sin desconocer dicho derecho, debe trascenderlo recurriendo: "a juicios de valor, sobre lo justo y lo injusto" (Atienza, 1997: p.10). Los jueces y tribunales deciden sobre los bienes más preciados de los seres humanos: la libertad, sus bienes materiales, su honor y prestigio. La función jurisdiccional es de enorme importancia. Es necesario que ella esté protegida por las mayores garantías. Se afirma, con incuestionable razón, que la primera de las garantías de la justicia es "evitar que quienes puedan imponer dichas sanciones pudieran ser parciales en el planteamiento y resolución del procedimiento" (Fernández, 1990: p.38).

Resulta fácil establecer si un Juez es o no parte en el proceso. Se trata de la denominada imparcialidad objetiva. Si el problema se redujera a determinar si el Juez y el Jurado son o no parte, el asunto no revestiría complejidad; pero no es suficiente con que el Juez o el Jurado no sean parte, es necesario que decidan el caso de que se ocupan sin que intervengan circunstancias ajenas a su función de hacer justicia; es lo que la doctrina denomina imparcialidad subjetiva (Montero et al 2000).

Como puede observarse, determinar cuándo un Juez actúa con imparcialidad no resulta tan fácil. Esto ha llevado al legislador a establecer una serie de casos y situaciones concretas y materialmente verificables, las cuales de concurrir en un Juez, permiten resumir que él no ofrece la garantía de imparcialidad necesaria para la administración de justicia, y debe separarse del caso, o ser separado.

En este sentido, el código de Procedimiento Civil Brasilero en su Artículo 5o, LIII enumera las causas que permiten presumir la parcialidad de un Juez, logrando con ello la objetivación de la imparcialidad.

El Juez debe retirarse del caso cuando entienda que en él concurren una o varias de las causas enunciadas en el artículo indicado anteriormente, es decir, debe inhibirse. En ausencia de inhibición, la parte interesada puede 
exigirle al Juez su separación del caso, recurriendo a la recusación. Ambas figuras jurídicas son consideradas como los instrumentos que garantizan la imparcialidad del Juez.

No obstante, y sin negar la utilidad de los instrumentos descritos, se comparte la idea de que no son suficientes todas las técnicas procesales vigentes para garantizar completamente al justiciable sus derechos contra los prejuicios que eventualmente pueda tener un Juez, y que se requiere además de jueces provistos de una ética fuerte.

El derecho a un Juez imparcial tiene categoría de derecho fundamental, lo que tanto enfatiza Rousseau en el "Contrato Social". La importancia de la existencia de jueces imparciales ha sido reconocida por los Estados modernos y democráticos, lo que explica su consagración y previsión en los tratados internacionales de mayor trascendencia mundial.

Si el Juez no se mantiene neutral y por razones políticas, económicas o de cualquier otra naturaleza, no aplica la norma jurídica vigente y en consecuencia se parcializa en beneficio de uno o cualquiera de los contendientes; pierde su condición y calidad para juzgar, deja de ser Juez y se convierte en una parte más del soberano. El sistema judicial en el cual ocurran tales desviaciones e inmoralidades pierde credibilidad y prestigio; no cumple con la misión que justifica su existencia, hacer justicia y contribuir al bienestar social es un deber libre y responsable (Rousseau, 1999).

En síntesis, el Juez garantista es aquel que vestido de la independencia funcional que le otorga la Constitución de cualquier república democrática aplica el derecho a los casos concretos que le son sometidos con el único compromiso de submisión a Dios, a la Constitución y a su propia conciencia, extrayendo así la regla jurídica que expresa las enseñanzas de la comunidad, convirtiendo a la justicia en una realidad social por medio de su decisión.

Por tanto, el ejercicio de la función jurisdiccional no puede ser apenas la submisión del Juez a la ley, sino principalmente al análisis crítico de su significado como medio de controlar su legitimidad constitucional. "O magistrado garantista deve buscar na Constituição a validade e justiça das leis aplicando-as de forma a solucionar os conflitos sociais, explicitando em sua decisão os valores supremos de uma sociedade fraterna, pluralista e sem preconceitos, fundada na harmonia social e comprometida, na ordem interna e internacional, com a solução pacífica de suas controvérsias" (CPRFB, 1988b: Art.5).

Y por último vale aquí "la lección de Tocqueville, de nada vale que se otorgue independencia a los jueces si, luego, ellos la entregan día a día para obtener una mejor posición, para hacer una carrera más brillante o para establecer relaciones políticas" (Colmer, 2000: p.30).

\section{El Jurado}

Aristóteles, filósofo griego de la Antiguedad Clásica, fue uno de los primeros en estudiar y analizar la vida del hombre en sociedad. Concluyó que somos sociales por naturaleza porque necesitamos de otros seres humanos 
para satisfacer las necesidades individuales básicas. Estas se satisfacen en grupo y es a través de la historia de la humanidad que se ha evidenciado que las personas se reúnen, forman familias y desarrollan comunidades. Hobbes, Locke y Maquiavelo escribieron sobre el paso del hombre del estado de naturaleza al estado social y posteriormente Rousseau le agregó a esas ideas un concepto original: la libertad e igualdad que existe en el estado de naturaleza y que en el estado social se deben legitimar no por la fuerza sino por una convención establecida entre todos los miembros del cuerpo que se tratan de constituir en sociedad.

Para vivir en sociedad, el hombre ha establecido formas de gobierno, con el propósito de reglamentar la conducta humana y de crear un balance entre los distintos intereses humanos (Rousseau, 1999). Por ello se establecen normas, se redactan leyes y se legisla.

Las leyes no son otra cosa que normas de conducta establecidas por los legisladores, las cuales informan sobre nuestras responsabilidades y derechos, y qué tipo de conducta es aceptada o prohibida.

Por virtud de la Constitución de cualquier país democrático, el Estado tiene un gobierno y para evitar la anarquía o la tiranía, se establece la doctrina de poderes (Montesquieu, 1984). El poder político se divide en el legislativo, el ejecutivo y el judicial. Reglamentar la conducta humana es responsabilidad de los legisladores. Estos redactan las leyes que rigen los estilos de vida de la sociedad. Al poder ejecutivo lo representa un gobernador o gobernante y entre sus funciones están el ejecutar las leyes para que las mismas se cumplan y garanticen una adecuada convivencia social y la seguridad del ciudadano.

En este caso, el poder judicial está representado por el Tribunal Supremo de Justicia y todos aquellos tribunales que se establecen para resolver las controversias características de la vida en sociedad y para garantizar que las personas que violan las leyes sean castigadas por sus actos ilegales.

El castigo es uno de los medios que el gobierno utiliza para asegurar el cumplimiento de las leyes. El Código Penal define la mayoría de las conductas ilegales o delitos y establece el castigo al ofensor. En este caso, el delito se define como una acción u omisión en contra de una ley que prohíbe u ordena la realización de determinado acto y que conlleva, al ser probado, una pena o sanción.

El propósito de las leyes es proteger a la sociedad; regular las relaciones de las personas; mantener un orden y control social para poder vivir en comunidad. Todo esto es necesario porque existen personas que realizan actos que son malos por naturaleza, como matar intencionalmente a un ser humano, o que no son necesariamente indeseables, pero sí indispensables para las buenas relaciones entre los ciudadanos, como las leyes que regulan el uso y disfrute de la propiedad. Para Rousseau, la ley es la expresión de la voluntad general de carácter sagrado pues representa el único modo de eliminar las arbitrariedades de los hombres particulares que tienen el poder (Rousseau, 1999).

Para enfrentar el problema de la criminalidad, que tanto afecta a la sociedad, el Gobierno delega parte de su poder ejecutivo en una serie de instituciones responsables de hacer cumplir las leyes, de investigar los delitos, 
identificar, localizar y arrestar al culpable, y llevarlo a responder ante el poder judicial por los actos cometidos contra el pueblo. También son responsables de custodiar y rehabilitar a las personas responsables de violar las leyes. Estas dependencias se conocen como el Sistema de Justicia. Por eso el objeto de las leyes es siempre general, nunca considera hombres ni acciones en particular. La ley no puede ser injusta, pues está hecha por el soberano, el pueblo como cuerpo; es nada más que el registro de la voluntad de cada uno.

El pueblo por sí mismo siempre desea el bien, siempre y cuando este esté preparado. Hay particulares que rechazan el bien común, de manera que todos tienen necesidad de guías, es decir, la necesidad de un legislador, una "ley pública", que una la voluntad y el entendimiento. Este legislador es entonces un ser extraordinario, pero por su cargo no puede dar fuerza ejecutiva a las leyes que redacta. Solo el soberano manda a los hombres; él manda las leyes.

Tan pronto un ciudadano comete un delito y este es reportado, la policía inicia un proceso investigativo dirigido a determinar quién o quiénes son los responsables de la violación de la ley. Con esto se inicia el aspecto procesal del derecho penal, el cual atraviesa por una serie de etapas que garantizan lo que se conoce como el debido proceso de ley dentro del Sistema de Justicia Criminal. Es un sistema porque sus funciones están entrelazadas entre sí y cada componente depende del otro para realizar su trabajo.

Los casos criminales, en los que hay una actuación a priori de los Jurados, tienen tres etapas fundamentales: los procedimientos anteriores al juicio, el juicio, y los procedimientos posteriores. Los procedimientos anteriores al juicio se inician con la intervención de una serie de organismos a los cuales se les han conferido facultades investigativas.

Como norma general, los primeros en acudir a la escena del crimen son los agentes de la Policía. Estos protegen el lugar donde se cometió el crimen y llevan a cabo una investigación preliminar. Cuando esta última se centra en una persona como el posible autor del delito (sospechoso) se prepara la denuncia y se obtiene la autorización de un fiscal para presentarla ante un magistrado, en una sala de investigaciones de un tribunal, con el propósito de que se determine causa probable para el arresto.

El fiscal presenta la denuncia ante un magistrado para que se determine causa probable y se expida una orden de arresto. La orden de arresto es la que expide un magistrado, con base en una denuncia, ordenándole al policía efectuar un arresto. Este se define como el acto de poner a una persona bajo custodia mediante la restricción de la libertad.

Luego del arresto, la policía tiene que llevar a la persona a un magistrado. Este último le fijará una fianza, lo citará para una vista preliminar, si el delito es grave, y le informará sus derechos constitucionales. Se hace necesario acotar que la fianza es y así debe considerarse, una medida cautelar que se aplica de forma semidiscrecional por el órgano judicial, por lo que puede aceptarse o denegarse. Posteriormente, se establecerá un juicio rápido y público, juicio por Jurado, en los delitos graves (dependiendo de los códigos penales de cada país democrático). 
Es un derecho constitucional el juicio por Jurado en los delitos de naturaleza grave. Puede ser renunciado y cuando esto ocurre el Juez será el único juzgador de las controversias relativas a los hechos y el derecho. Tomará la alegación del acusado; admitirá y examinará la evidencia; escuchará a la partes y a los testigos; y procederá a determinar culpabilidad o inocencia.

El juicio por Jurado se celebra en una de las salas del Tribunal de Justicia. Se inicia cuando el secretario llama a las partes relacionadas con el caso. De estar todos presentes, se procede a la selección del Jurado (depende del Código Penal de cada país). En el caso de Brasil, consiste de 21 personas, de las cuales siete son seleccionadas por sorteo. No pueden ser: mayores de 60 años de edad, menores de 21 años, analfabetos, sordo-mudos, sordos, ciegos, ciudadanos sin derecho a voto y familiares del reo, Juez o Fiscal (CPRFB, 1988a: Art. 434 y 436). Su responsabilidad será resolver las controversias relacionadas con los hechos y deliberar para determinar culpabilidad o inocencia.

Luego de seleccionar y juramentar a los miembros del Jurado, se procede a dar lectura a la acusación y alegación. El primer turno lo tiene el Fiscal. Durante el juicio, le corresponde demostrar con evidencia la culpabilidad del acusado, más allá de duda razonable. Este requerimiento es de naturaleza constitucional y protege a las personas de ser encarceladas sin pruebas suficientes. En su primer turno, el Fiscal expone su teoría sobre cómo habrá de probar su caso. Presenta las pruebas y llama a testificar a cada unos de sus testigos (si los hubiera).

Estos son interrogados y luego contra-interrogados por el abogado del acusado. El segundo turno lo tiene la defensa, quien también presenta su teoría, testigos y pruebas. Cada una de las partes tiene la oportunidad de presentar prueba de refutación. Luego se presentan los informes finales. El Juez procede a dar las instrucciones necesarias para que el Jurado pueda tomar una determinación. Se les toma juramento y son llevados a un salón para deliberar.

La deliberación se refiere a la discusión y evaluación de la prueba, por el Jurado, para determinar la culpabilidad o inocencia del acusado. Cuando se ponen de acuerdo, regresan a la sala e informan al Juez el veredicto. Si la persona es encontrada culpable, se le cita para el acto de lectura de sentencia.

Hasta aquí, he realizado un comentario descriptivo del proceso legal para llegar a un juicio por Jurado. Ahora expondré algunas ideas respecto al Jurado. Personas libres, convocadas a participar de un acto de libertad o condena de una persona, haciendo uso del poder político soberano que se asume en el contrato o pacto social que expone Rousseau.

¿Cómo una multitud ciega, que a menudo no sabe lo que quiere, porque rara vez sabe lo que es bueno para ella, ejecutaría por sí misma una empresa tan grande, tan difícil, como un sistema de legislación? (Rousseau, 1999: p.49).

Rousseau fue uno de los doctrinarios fundamentales de la Revolución Francesa (1789). A partir de este evento histórico se iniciaron en el mundo los gobiernos democráticos. Pero como ocurre con todos estos teóricos, los 
políticos los ponen a decir lo que ellos quieren. Por eso puede ser útil señalar dos aspectos muy concretos de la doctrina de este autor, tan mencionado cuando se apela constantemente al pueblo para cualquier decisión importante, que en este caso es convocado para hacer parte del Jurado del Tribunal de Justicia.

El primero se refiere a la Ley. La primera gran preocupación de Rousseau fue que la Ley expresara fielmente la voluntad popular. ¿Por qué? Porque él desea que no sea la voluntad de una sola persona, el Rey, quien tenga la última palabra, sino que la ley sea la más alta expresión de la comunidad política. En carta al Marqués de Mirabeau le decía: "he aquí entre mis viejas ideas, el gran problema de la política, que yo comparo al de la cuadratura del círculo en geometría... Encontrar una forma de gobierno que ponga la ley por encima del hombre" (Rousseau, 1999: p.43). Ni reyes, ni autócratas quería Rousseau, sino un orden jurídico al que estuvieran sometidos, por igual, gobernados y gobernantes. Un regreso a los gobiernos autoritarios no es progreso sino retroceso y, por supuesto, no se ajusta a la doctrina de Rousseau que abogaba por la sumisión de los gobernantes al imperio de la ley.

El segundo se refiere a las serias dudas que Rousseau tenía sobre la capacidad de ese pueblo, a quien buscaba liberar de la tiranía, para que se auto-gobernara, por no estar suficientemente capacitado. El teórico de la soberanía popular tiene "serias dudas" de que el pueblo tenga la capacidad para una tarea "tan grande, tan difícil, como un sistema de legislación", lo que pone de manifiesto su agudeza de pensamiento y su honestidad intelectual.

Dos conclusiones parece que son obvias. La primera es que para preservar el ejercicio de los derechos fundamentales del ser humano, el Estado debe organizarse de tal manera que la ley esté por encima de gobernados y de gobernantes, lo que supone el respeto a las instituciones. Esto se practica en países donde su Presidente esté sometido a juicio político, acusado de perjurio, es decir, por mentir bajo juramento, quebrando la Ley. Eso le puede costar el cargo.

La segunda conclusión es que cuando se afirma que el pueblo tendrá la palabra final en todo, desde hacer una nueva Constitución, decidir el programa económico del gobierno, ser partícipe de las políticas públicas y obvimente participar de los juzgamientos de personas acusadas de cometer actos ilegales contra la sociedad. Legalmente se incurre en una afirmación de corte populista porque el padre de la democracia dudó seriamente de que una tarea tan compleja deba dejarse en las manos del pueblo sin antes haberlo educado y capacitado para ser el soberano.

El hecho de que las personas convocadas a ser parte del Jurado en cualquier Tribunal de Justicia sean de clase media, tengan una formación mínima obligatoria y sean ciudadános legítimos con derecho a voto no es garantía de idoneidad para participar de tal acto. No todos conocen el vocabulario utilizado en esos recintos, no hay democracia en la participación porque son convocados y sorteados, y por último se cuestiona la decisión del veredicto por la influencia social y cultural que existe en el medio.

Por otro lado, el pueblo es utilizado sin que él ni siquiera lo perciba, para estructurar un orden jurídico que lo mismo puede beneficiarlo que perjudicarlo. Cuando le lleguen sus efectos, positivos o negativos, ya estará 
sujeto a ese orden nuevo, que ojalá sea mejor pero que puede también no serlo porque el pueblo "a menudo no sabe lo que quiere... porque rara vez sabe lo que es bueno para él”, dice Rousseau (1999: p.28).

En un juzgamiento en la sala plenaria, estando presentes el Juez, el Fiscal, el Jurado, el Abogado Defensor, el reo y el público, el Secretario da lectura sucinta del caso, el Juez con sus palabras acomodadas y rebuscadas pronuncia para que la (el) Secretaria/o escriba el informe preliminar del caso a resolverse.

Una vez que se escuchan los argumentos de las partes, acusaciones, defensas y testimonios, los miembros del Jurado se dirigen a la sala secreta junto con el Juez, el Abogado y el Fiscal representante del Estado.

El Juez elabora las preguntas para que el Jurado en el momento del veredicto final vote para la condena o liberación del reo. Las incógnitas son: ¿por qué el Juez hace las preguntas con su vocabulario técnico que solo los juristas entienden?, ¿qué conocimientos previos sobre el caso tienen los Jurados?, y ¿quién garantiza que las preguntas estén elaboradas imparcialmente?...

En otras palabras, el pueblo aprobará o desaprobará lo que un "pequeño cogollo" redacte en su nombre para regir su destino o en su nombre dar su veredicto. El pueblo solo dirá sí o no. Y como a menudo "no sabe lo que quiere”, poco valor tienen ese sí o ese no (Rousseau, 1999).

En la actualidad, hay un generalizado sentimiento de frustración ante los resultados de este tipo de juicios. Y son expresadas en congresos, simposios y conferencias varias sugerencias, tratando básicamente de resolver este problema de incapacidad y falta de conocimiento por parte de los Jurados. Es este el meollo de la cuestión: decisiones injustas, por fallas evidentes causadas por la arbitrariedad de los jueces, incompetencia y alta dosis de manipulación ideológica.

En este contexto, dice el Profesor Antonio Torres “aún, a mi ver, tienen el coraje de hablar los jueces sobre aquello que, constituyéndose en su marca registrada, ha sido su real 'talón-de-Aquiles': las decisiones secretas" (Torres, 2005: p.10). El juicio público ha sido creado para respaldar la integridad y la imparcialidad de los juicios, sin embargo, el sigilo de las votaciones, a lo largo del tiempo ha sufrido un increíble proceso de degeneración, sirviendo para tapar el cambio de favores personales, políticos, raciales y hasta económico-financieros.

Y los reos que están puestos en el más alto nivel de la pirámide social usan y abusan de esa prerrogativa. Es claro que esos hechos son traídos al conocimiento público sin condiciones de prueba, pues nadie pasa recibo en materia de corrupción. Está claro, también, que la mayoría de los Jurados son honestos; sin embargo, la ocurrencia de esos hechos deshonra, de forma irreparable, el criterio de la votación sigilosa.

Con seguridad, dirán algunos: “¡ve!, eso es una prescripción constitucional”. En el caso de Brasil, La Carta Magna, en su Art.50, inciso XXXVIII, mantiene la institución del Jurado con el sigilo de las votaciones pero, al mismo tiempo, en su Art. 93, inciso IX, dice, de manera categórica, que “... todos los juicios de los órganos del Poder Judiciario serán públicos y, fundamentadas to- das las decisiones, bajo pena de nulidad...” ¿Y ahora? 
El Tribunal de Justicia integra el Poder Judiciario (Art.11, inciso II de la Ley de Organización Judiciaria del Estado) y sus integrantes son Jueces con privativa capacidad para sus funciones.

Y de allí, el Código de Proceso Penal, en su Art. 438, impone a ellos, los Jurados, la misma responsabilidad en el ejercicio de la función jurisdiccional, que es reservada a los jueces togados.

Un Jurado puede ser responsabilizado civil y criminalmente por corrupción activa o pasiva, pero eso no ocurre, pues al decidir por el voto secreto, el Jurado no fundamenta su decisión. Y sin declaración de voto, el sistema jurídico queda a la merced de factores aleatorios, que pueden influenciar un juicio, hiriendo de muerte el principio del debido proceso legal.

Y más, con esa total ausencia de transparencia, es imposible punir a un Jurado corrupto, por inaccesible y lleno de subjetivismo.

Es más, ¿dónde queda el sagrado y universal derecho de un acusado a saber los reales fundamentos de una decisión que vale por una vida? ¿Qué motivos llevan, realmente, a un Jurado/Juez a absolver y lo que es peor, a condenar a un reo? En ese sistema, ¿qué seguridades recibe un ciudadano común de tener un juicio justo?

Hay muchos casos de Jurados que votan contra el reo por no "simpatizar" con su Abogado, porque el acusado es negro, indio o pobre; y en otros casos que absuelve a un criminal por simpatizar con el Fiscal o con el Abogado Defensor. ¿Eso es justo?, ¿será legal?, ¿será ético? ¿Cómo evitar esas atrocidades y arbitrariedades? Si todos tenemos los mismos derechos como miembros soberanos de una socidead, se justifica nuevamente lo que dice Rousseau: ¿cómo un pueblo ignorante puede decidir, si pocas veces dice lo que quiere porque no sabe lo que es bueno para él?

La votación secreta es, en la práctica, un secreto disfrazado de legitimidad. En las pequeñas comunidades, donde las fuerzas económico-política-partidarias imperan en todos los sectores, los juicios son "arreglados" en la víspera, generalmente en las residencias de los dueños del poder local y toda la población ya conoce los resultados con la debida antecedencia, incluso, para disponer y preparar la mejor fiesta.

Del mismo modo en los grandes centros, cuando el Jurado decide en unanimidad ese tal sigilo, ¿va o no para el espacio? Así y a rigor, por regla constitucional, todo juicio que envolviese una unanimidad debía ser nulo pues, en verdad, comprometida estaría la votación con la divulgación a las descubiertas de los votos de los miembros de Jurado. Y, si eso no sucede en nombre de la "soberanía del Jurado", ¿cómo entonces sería mantenida esta farsa con aires de legalidad? 


\section{Conclusiones}

Se tiene conocimiento de situaciones escabrosas, donde conciencias han sido compradas y vendidas. Además, por el valor de algunos negocios, por algunos precios humillantes, han sido literalmente transformadas ciertas conciencias en mercancía de bajo valor. Célebre crónica: “... una cosa es robar gallinas, otra es robar conciencias; se sabe por qué y para qué se roban gallinas. La gran diferencia es que nunca se sabe para qué se roban conciencias".

Simón Bolívar, refiriéndose al Contrato Social dijo: "La soberanía del pueblo no es ilimitada, porque la justicia es su base y la utilidad perfecta le pone término" (Romero, 1822). En otras palabras, que la ética y el derecho natural constituyen un límite a la soberanía popular. Dicho sea de paso, si el soberano, emocionado, decide eliminar los derechos naturales del hombre, tal decisión, aun aprobada por el ciento por ciento del pueblo, carece de validez; porque aupar la omnipotencia del pueblo es tan malo como aupar la omnipotencia de un autócrata. 


\section{Bibliografía}

Aristóteles (1984). Gran Ética. Madrid: Editorial Sarpe.

Atienza, M. (1997). Tras la Justicia. Barcelona: Editorial Ariel, S.A.

Beccaria, C. (s/f). Dos delitos e das penas. Trad. Torrieri Gumarães. Brasil: Ed. Hemus - Livraría Editora Ltda.

Colmer, J. L. (2000). Derecho Jurisdiccional, 9 edicao, Valencia: Tirant Lo Blanch.

CPRFB (1988a). Capítulo II del Código de Proceso Penal de la República Federativo del Brasil, del Proceso de los Crímenes - Competencia del Jurado. Art. 434 y Art. 436. Accesible en: http://pdba.georgetown.edu/Constitutions/Brazil/esp88.htmll\#mozTocId272959

CPRFB (1988b). Constitución Política de la República Federativa de Brasil. De los Derechos y Deberes Individuales y Colecti- vos, Título II, capítulo I, Art. 5. Accesible en: http://pdba.georgetown.edu/Constitutions/ Brazil/esp88.html\#mozTocId272959

Fernández, E. (1990). La reforma del proceso penal. Madrid: Tecnos. Accesible en: http://biblio.juridicas.unam.mx/revista/DerechoComparado/numero/89/art/art1.htm\#N15

Godwin, W. (1945). Investigación acerca de la Justicia Política. Buenos Aires: Ed. Americalee. Trad. J. Prince.

Hobbes, T. (1984). Leviatán (o de la materia, forma y poder de una república eclesiástica y civil). Madrid: Editorial Sarpe.

Montero, J., Gómez, L., Montón, A., Ba- rona, S. (2000). Derecho Jurisdiccional. Va- lencia: Edición Tirant Lobllanch.

Montesquieu, R. (1984). Del Espíritu de las Leyes. Madrid: Editorial Sarpe.

Romero, C. (1822). "Simón Bolívar y la Justicia. Síntesis del discurso de Carmen Mercedes de Romero en la celebración del CCXXVI aniversario del natalicio de Simón Bolívar”. Accesible en: http://tsj-dem.gob. ve/jsp/coberturas/index.jsp

Rousseau, J.J. (1999). El Contrato Social. Libro II, Cap. VI. Versión portuguesa. Trad. de Rolando R. Dasilva. Brasil: Ed. Cultrix.

Schritmeyer, A. (2001). Controlando o Poder de matar uma leitura antropológica do Júriritual lúdico y teatralizado .- Tese para obtenção do título de Doutorado. São Paulo.

Torres, A. (2005). Conferencia de 1o Tribunal do Juri da Comarca de Campina Grande, Porto Vello, Brasil. 
